\title{
Effect of Surface Carbon Structure on the Electrochemical Performance of $\mathrm{LiFePO}_{4}$
}

\author{
Marca M. Doeff, ${ }^{*}$ Yaoqin Hu, ${ }^{*}$ Frank McLarnon, $\dagger$ and Robert Kostecki $\uparrow$ \\ *Materials Sciences Division \\ and \\ ${ }^{\dagger}$ Environmental Energy Technologies Division \\ Lawrence Berkeley National Laboratory \\ University of California \\ Berkeley, CA 94720, USA
}

\section{Acknowledgments}

This work was supported by the Assistant Secretary for Energy Efficiency and Renewable Energy, Office of FreedomCAR and Vehicle Technologies of the U.S. Department of Energy under Contract No. DE-AC03-76SF00098. Y. H. would like to thank the Chinese Ministry of Education for financial support. 


\begin{abstract}
The electrochemical performance of $\mathrm{LiFePO}_{4}$ samples synthesized by sol-gel or solidstate routes was found to vary considerably, although their physical characteristics are similar. Raman microprobe spectroscopic analysis indicated that the structure of the residual carbon present on the surfaces of the powders differs significantly and accounts for the performance variation. Higher utilization is associated with a larger ratio of $\mathrm{sp}^{2}$ coordinated carbon, which exhibits better electronic properties than disordered or $\mathrm{sp}^{3}-$ coordinated carbonaceous materials. Incorporation of naphthalenetetracarboxylicdianhydride during synthesis results in a more graphitic carbon coating and improves utilization of $\mathrm{LiFePO}_{4}$ in lithium cells, although the total carbon content is not necessarily higher than that of samples prepared without the additive. This result suggests that practical energy density need not be sacrificed for power density, provided that carbon coatings are optimized by carefully choosing additives.
\end{abstract}


$\mathrm{LiFePO}_{4}$ has recently been proposed for use as a potentially low-cost, environmentally benign, and safe alternative to $\mathrm{LiCoO}_{2}$ cathode materials for rechargeable lithium batteries. ${ }^{1}$ Rate limitations make it difficult to achieve full utilization of this material near room temperature and at moderate current densities, although the theoretical capacity of $170 \mathrm{mAh} / \mathrm{g}$, based on the two-phase reaction ${ }^{2} \mathrm{LiFePO}_{4} \leftrightarrow \mathrm{FePO}_{4}+\mathrm{Li}^{+}+\mathrm{e}^{-}$, is attractive. The poor rate capability has been attributed to low electronic conductivity and/or slow diffusion of lithium ions across the two-phase boundary. To address these issues, researchers have optimized synthesis techniques to minimize particle size without compromising purity ${ }^{3}$ or have incorporated additives to increase conductivity. The latter approach includes coating $\mathrm{LiFePO}_{4}$ particles with carbon by incorporating an organic or polymeric component with the precursors before firing, ${ }^{4,5}$, adding metal particles to the mix,. ${ }^{6}$ or solid-solution doping by metals supervalent to $\mathrm{Li}^{+}{ }^{7}$ All have met with success in improving performance. It has recently been pointed out, however, that small particle sizes adversely affect tap densities. ${ }^{8}$ Even small amounts of carbon additive exacerbate this effect, resulting in an electrode with an unrealistically low practical energy density. So that neither energy nor power density are unduly compromised, it is imperative to optimize carefully the carbon coating in composite $\mathrm{LiFePO}_{4}$ materials. To this end, we have initiated a study on the effect of the structure of residual (less than 2 wt. \%) carbon on electrochemical performance of $\mathrm{LiFePO}_{4}$ materials. Herein, we describe preliminary results.

\section{Experimental}

$\mathrm{LiFePO}_{4}$ samples were made by a solid-state reaction and by a sol-gel process. For the solid-state method, a modification of the procedure of Yamada et al. was used. ${ }^{3}$ 
$\mathrm{Li}_{2} \mathrm{CO}_{3}$ (lithium carbonate, Mallinckrodt), $\mathrm{Fe}(\mathrm{II}) \mathrm{CH}_{3} \mathrm{CO}_{2} 2 \mathrm{H}_{2} \mathrm{O}$ (iron acetate, Aldrich) and $\left(\mathrm{NH}_{4}\right) \mathrm{H}_{2} \mathrm{PO}_{4}$ (Dihydrogen ammonium phosphate, EM Sciences) were ground together thoroughly under $\mathrm{N}_{2}$ to avoid oxidation. The mixture was then heated at $300^{\circ} \mathrm{C}$ under flowing $\mathrm{N}_{2}$ for ten hours to decompose the acetate and phosphate. The powder was then ground again in a planetary ball mill for 30 minutes and heated to $600^{\circ} \mathrm{C}$ under flowing $\mathrm{N}_{2}$ gas for eight hours.

For sol-gel samples, the starting materials were $\mathrm{Fe}\left(\mathrm{NO}_{3}\right)_{3} 9 \mathrm{H}_{2} \mathrm{O}$ (iron nitrate, Aldrich), $\mathrm{Li}\left(\mathrm{CH}_{3} \mathrm{COO}\right)_{2} 2 \mathrm{H}_{2} \mathrm{O}$ (lithium acetate, Aldrich), $\mathrm{H}_{3} \mathrm{PO}_{4}$ (phosphoric acid, Sigma) and $\mathrm{HOCH}_{2} \mathrm{COOH}$ (glycolic acid, Aldrich). The metal compounds were first dissolved in phosphoric acid and de-ionized water. This solution was mixed until homogeneous and was added to glycolic acid (1:2 metal:glycolic acid ratio). Ammonium hydroxide was added to the solution to adjust the $\mathrm{pH}$ to between 8.5 and 9.5. The solution was then heated at $70-80^{\circ} \mathrm{C}$ under $\mathrm{N}_{2}$ until a gel formed. The gel was transferred to an alumina boat, heated slowly to $500^{\circ} \mathrm{C}$ under flowing $\mathrm{N}_{2}$, and decomposed at that temperature for ten hours. The resultant powders were then ground, dried, and heated to 600 or $700^{\circ} \mathrm{C}$ under a flow of $\mathrm{N}_{2}$ gas, for 5-15 hours. For some samples, 4 wt. \% naphthalenetetracarboxylicdianhydride was added during the grinding step, before a final heating at $600^{\circ} \mathrm{C}$ for ten hours. More complete processing details and descriptions of these materials will be presented in a subsequent publication.

A Siemens D5000 diffractometer was used to obtain x-ray powder diffraction patterns for the samples, using $\mathrm{Cu} \mathrm{K} \alpha$ radiation $(\lambda=1.54 \mathrm{~A})$. Particle sizes were determined with a Beckman Coulter particle size analyzer (model LS 230, with small volume module) and a scanning electron microscope (ISI-DS 130C dual stage) was used 
to observe the particle morphologies. Elemental carbon analysis of samples was performed by Luvak Inc. (Boylston, MA).

An integrated Raman microscope system "Labram" made by ISA Groupe Horiba was used to analyze the structure and composition of individual particles of $\mathrm{LiFePO}_{4}$. The excitation wavelength was supplied by an internal He-Ne (632 nm) $10 \mathrm{~mW}$ laser. The power of the laser beam was adjusted to $0.1 \mathrm{~mW}$ with neutral filters of various optical densities. The size of the laser beam at the sample was $\sim 1.2 \mu \mathrm{m}$.

Laminated electrodes containing 80 wt.\% active material, 8 wt.\% Kynar PVdF binder (grade 2801-00, lot \#97C8118, Elf Atochem North America, Inc., Technical Polymers Department), 6 wt.\% SFG-6 synthetic flake graphite (Timcal Ltd., Graphites and Technologies) and $6 \mathrm{wt} \%$ compressed acetylene black were prepared by spreading a slurry in N-methyl methylpyrrolidone onto aluminum foil current collectors and allowing them to dry. A small amount of Pelseal Bonding Agent 65 (Pelseal Technologies, LLC) was also added to the slurry, according to the manufacturer's directions, to prevent cracking. Electrodes were dried overnight in air and then in a $120^{\circ} \mathrm{C}$ vacuum oven for at least 8 hours. For coin cells with lithium anodes, $1.8 \mathrm{~cm}^{2}$ electrodes were punched out and weighed individually to determine loading. This loading typically corresponded to 5$15 \mathrm{mg} / \mathrm{cm}^{2}$ of active material. 2032 size coin cells were assembled in a helium-filled glove-box, using lithium metal as a counter electrode and $1 \mathrm{M} \mathrm{LiPF} 6$ in 1:2 ethylene carbonate/dimethyl carbonate (EC/DMC) electrolyte solution.

Cells were cycled galvanostatically at a current density of $0.055 \mathrm{~mA} / \mathrm{cm}^{2}$ between 2.5 and 3.9 V at room temperature, using a Macpile II galvanostat/potentiostat (Bio-Logic SA, Claix, France). 


\section{Results and Discussion}

All $\mathrm{LiFePO}_{4}$ samples made by sol-gel or by solid-state synthesis from iron acetate are phase-pure according to their XRD patterns. Scanning electron micrographs show that powders made by sol-gel consist of sub-micron particles with a flake morphology partially or fully fused together into larger agglomerates. The mean sizes of these agglomerates varied with the synthesis conditions and ranged from about 5 to $110 \mu \mathrm{m}$. Sample 3A (prepared by solid-state reaction) consisted of somewhat porous, irregularly shaped particles with a mean size of $17 \mu \mathrm{m}$. For particle sizes above $20 \mu \mathrm{m}$, utilization in lithium cells scaled inversely with the mean primary particle size of the $\mathrm{LiFePO}_{4}$ samples and was generally poor. Below $20 \mu \mathrm{m}$, however, there was no clear-cut relationship between capacity obtained in lithium cells and mean primary particle size. ${ }^{9}$

The $\mathrm{LiFePO}_{4}$ powders, which range in color from light to dark gray, always contain residual carbon resulting from combustion of organic moieties in the precursors. Sol-gel samples had 0.4-0.7 wt. \% carbon and were lighter in color than sample 3A, (1.47 wt. \% residual carbon) made by solid-state synthesis from iron acetate. Interestingly, performance was not necessarily better for sol-gel samples with higher carbon contents, although sample 3A, with the highest residual carbon content, outperformed all sol-gel samples processed without additives. These observations indicate that factors beside particle size and carbon content are responsible for the observed variations in the electrochemical characteristics of $\mathrm{LiFePO}_{4}$ powders.

To investigate this phenomenon further, Raman microprobe spectroscopy was employed. The Raman spectra of sol-gel and 3A materials with mean primary particle sizes below $20 \mu \mathrm{m}$ are shown in Figure 1. All Raman spectra consisted of a relatively 
small band at $940 \mathrm{~cm}^{-1}$, which corresponds to the symmetric $\mathrm{PO}_{4}$ stretching vibration of $\mathrm{LiFePO}_{4}$, and intense broad bands at 1350 and $1580 \mathrm{~cm}^{-1}$ that can be assigned to the $\mathrm{D}$ and $\mathrm{G}$ bands of residual carbon, respectively. The relative intensity of the D band $v s . \mathrm{G}$ band is attributed to increased carbon disorder, for example, in microcrystalline graphite. ${ }^{10}$ Tuinstra and Koenig ${ }^{11}$ showed that the ratio of D/G integrated peak intensities is inversely proportional to the intra-planar microcrystallite distance, $\mathrm{L}_{\mathrm{a}}$. Thus, the Raman spectra of the samples are consistent with $\mathrm{LiFePO}_{4}$ uniformly coated with a highly defective nanocrystalline carbon with a significant contribution from various short-order $\mathrm{sp}^{2}$ and $\mathrm{sp}^{3}$ types of carbon and functional groups adsorbed on the surface.

The structure and physicochemical properties of carbon produced from organic precursors change dramatically as a function of the pyrolysis temperature in the range from 600 to $1000^{\circ} \mathrm{C} .^{12}$ Current-sensing $\mathrm{AFM}$ and four-point probe measurements revealed that the carbons produced at a low pyrolysis temperature $\left(600^{\circ} \mathrm{C}\right)$ have low electronic conductivity, but the conductivity increased dramatically for carbons obtained at temperatures above $700^{\circ} \mathrm{C} . .^{13,14}$

We found that there is a strong correlation between the structure of residual carbon and $\mathrm{LiFePO}_{4}$ utilization in lithium cells at $0.055 \mathrm{~mA} / \mathrm{cm}^{2}$. To resolve the Raman spectra of carbon in our samples, we applied a standard peak deconvolution procedure. Band fitting with two carbon $\mathrm{D}$ and $\mathrm{G}$ lines did not give accurate results, thus four Gaussian bands were necessary to account for the observed Raman features with minimum error. Those four band locations are 1194, 1347, 1510 and $1585 \mathrm{~cm}^{-1}$. The positions of these bands varied very little between samples, however, their intensities changed significantly. The bands at 1591 and $1347 \mathrm{~cm}^{-1}$ can be assigned to the $\mathrm{E}_{2 \mathrm{~g}}$ 
graphite mode, and the $A_{1 g}$ mode associated with the breakage of symmetry occurring at the edges of graphite sheets, respectively. The bands at 1194 and $1510 \mathrm{~cm}^{-1}$ are assigned to tetrahedral carbon and $\mathrm{sp}^{3}$-type material, respectively, which are often observed in highly amorphous carbonaceous materials.

Figure 2 shows a relationship between the $\mathrm{LiFePO}_{4}$ utilization and the integrated Raman intensity ratios of $\mathrm{D} / \mathrm{G}$ bands and $\mathrm{sp}^{3} / \mathrm{sp}^{2}$ coordinated carbon. Both intensity ratios decrease steadily with higher utilization of $\mathrm{LiFePO}_{4}$ in the composite cathode. This trend can be interpreted by in terms of the increasing amount of larger graphene clusters in the very disordered carbon structure, and consequently, improved electronic conductivity of the carbon deposit. Improved electronic properties of the residual carbon can assure good contact between sub-micron particles within large agglomerates, and this intimate contact can predetermine their electrochemical performance. These results indicate that it should be possible to minimize the amount of conductive coating on $\mathrm{LiFePO}_{4}$, provided that additives are chosen to give carbons with low $\mathrm{D} / \mathrm{G}$ ratios and good electronic properties.

Organic compounds most likely to pyrolyze to form more highly graphitized carbons contain aromatic ring systems. An example is perylenetetracarboxylicdianhydride, which gives graphite-like films under certain conditions. ${ }^{15}$ Unfortunately, this compound is poorly soluble in common solvents, making it difficult to disperse evenly over $\mathrm{LiFePO}_{4}$ precursors. For this reason, we chose naphthalenetetracarboxylicdianhydride (I), which has better solubility than the perylene analog. 


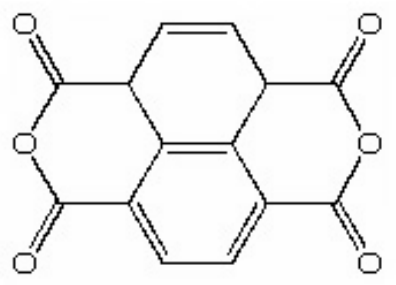

(I)

Sol-gel $\mathrm{LiFePO}_{4}$ powders processed with naphthalenetetracarboxylicdianhydride were gray-black in color and contained $1.15-1.21 \%$ total carbon by weight. Raman analysis shows that the surface carbon has a higher content of graphene clusters than $3 \mathrm{~A}$ and sol-gel prepared samples (see Figures 1,2). The discharge profile of a cell with a sample 1C2 cathode, made with naphthalenetetracarboxylicdianhydride, is compared to those of 7SG, 15SG, and 3A, made without additives, in Figure (3). Utilization is increased by about $25 \%$ for $1 \mathrm{C} 2$ over that of $7 \mathrm{SG}$, processed identically without the additive, and more than $40 \%$ for $15 \mathrm{SG}$, which was heated five hours longer at $600^{\circ} \mathrm{C}$ than were 7SG and 1C2. The physical characteristics of the sol-gel samples are similar, but the carbon content varies: $0.4 \%$ for $15 \mathrm{SG}, 0.69 \%$ for $7 \mathrm{SG}$, and $1.15 \%$ for $1 \mathrm{C} 2$. Significantly, $1 \mathrm{C} 2$ also outperforms $3 \mathrm{~A}$, which contains more carbon $(1.5 \%)$.

We are continuing our investigations into the optimization of conductive coatings on lowcarbon-content $\mathrm{LiFePO}_{4}$ samples. Configurations used to demonstrate high power density in cells containing $\mathrm{LiFePO}_{4}$ electrodes are, at present, unrealistic due to the large sacrifice in volumetric energy density associated with very thin electrodes and high carbon contents. A better understanding of the structure of carbon on the surfaces of $\mathrm{LiFePO}_{4}$ electrode materials should allow coating amounts to be minimized, so that high power can be achieved without an undue sacrifice in energy density. 


\section{Conclusions}

A comparison of $\mathrm{LiFePO}_{4}$ samples made by sol-gel and solid-state methods indicates that higher discharge capacities obtained in lithium cells are correlated with the structure and electronic conductivity of residual carbon on particle surfaces. By incorporating small amounts of a polyaromatic additive during synthesis of the sol-gel materials, a carbon coating with increased $\mathrm{sp}^{2}$ character could be produced, resulting in enhanced performance over samples with similar physical characteristics, even those with higher overall carbon contents. This result implies that it should be possible to minimize carbon content by optimizing the structure and coverage of carbon on particle surfaces.

\section{Acknowledgments}

This work was supported by the Assistant Secretary for Energy Efficiency and Renewable Energy, Office of FreedomCAR and Vehicle Technologies of the U.S. Department of Energy under Contract No. DE-AC03-76SF00098. Y. H. would like to thank the Chinese Ministry of Education for financial support.

\section{References}

1. A. K. Padhi, K. S. Nanjundaswamy, and J. B. Goodenough, J. Electrochem. Soc., 144, 1189 (1997).

2. A. S. Andersson, B. Kalska, L. Haggstrom, J. O. Thomas, Solid State Ionics, 130, 41 (2000).

3. A. Yamada, S. C. Chung and K. Hinokuma, J. Electrochem. Soc., 148, A224 (2001).

4. H. Huang, S.-C. Yin, and L.F. Nazar, Electrochem. and Solid State Letters, 4, A170 (2001).

5. N. Ravet, S. Besner, M. Simoneau, A. Vallee, M. Armand, J.-F. Magnan, European Patent Brevet EP 1 049182 A2, 2000.

6. F. Croce, A. D’Epifanio, J. Hassoun, A. Deptula, T. Olczac, and B. Scrosati, Electrochem. and Solid State Letters, 5, A47 (2002).

7. S-Y. Chung, J. T. Bloking and Y-M. Chiang, Nature Mater. 2, 123 (2002).

8. Z. Chen and J. R. Dahn, J. Electrochem. Soc., 149, All84 (2002).

9. Y. Hu, M. M. Doeff, R. Kostecki, and R. Fiñones, manuscript in preparation.

10. R. Vidano, D.B. Fischbach, J. Amer. Ceramic Soc. 61, 13 (1978).

11. F. Tuinstra and J. L. Koenig, J. Chem. Phys. 53, 1126 (1976).

12. R. Kostecki, B. Schnyder, D. Alliata, X. Song, K. Kinoshita, R. Kötz, Thin Solid Films, 396, 36 (2001). 
13. D. Alliata, R. Kostecki, X. Song, K. Kinoshita, R. Kötz, Electrochemical/Interfacial Studies of Carbon Films in Non-aqueous Electrolytes, $10^{\text {th }}$ International Meeting on Lithium Batteries, May 28-June 2, 2000, Como, Italy, Meeting Abstracts no. 68.

14. Z. Sun, X. Shi, X. Wang, Y. Sun, Diamond and Related Materials, 8, 1107 (1999)

15. K. Kamiya, T. Noda, M. Ide, and J. Tanaka, Synthetic Metals, 71, 1765 (1995). 


\section{Figure Captions}

Figure 1. Raman spectra of $\mathrm{LiFePO}_{4}$ powders. From top to bottom: Samples 12SGA (58 mAh/g), 15SG (77 mAh/g), 7SG (106 mAh/g), 3A (120 mAh/g), and 1C2 sol-gel $\mathrm{LiFePO}_{4}$ powder processed with naphthalenetetracarboxylicdianhydride $(126 \mathrm{mAh} / \mathrm{g})$. Samples designated \#SG (where \# represents a batch number) were prepared by a sol-gel process, and 3A was prepared by solid-state synthesis from iron acetate).

Figure 2. Electrochemical discharge capacity of $\mathrm{LiFePO}_{4}$ electrodes in lithium cells vs. structure of residual carbon. Decreasing D/G and sp3/sp2 band ratios indicate increased amounts of graphene clusters in the structure.

Figure 3. Discharges of Li/1M LiPF 6 , EC-DMC/LiFePO 4 cells at $0.055 \mathrm{~mA} / \mathrm{cm}^{2}$ : Sample 1C2 made by sol-gel with naphthalenetetracarboxylicdianhydride, containing $1.15 \%$ total $\mathrm{C}(-), 3 \mathrm{~A}$ made by solid-state synthesis from iron acetate, containing $1.5 \%$ total carbon (- -), 7SG made by sol-gel with no additives, containing $0.69 \%$ total carbon (-----) and 15SG made by sol-gel with no additives, containing $0.4 \%$ total carbon ( $\left.{ }^{\cdots \cdots}\right)$. 


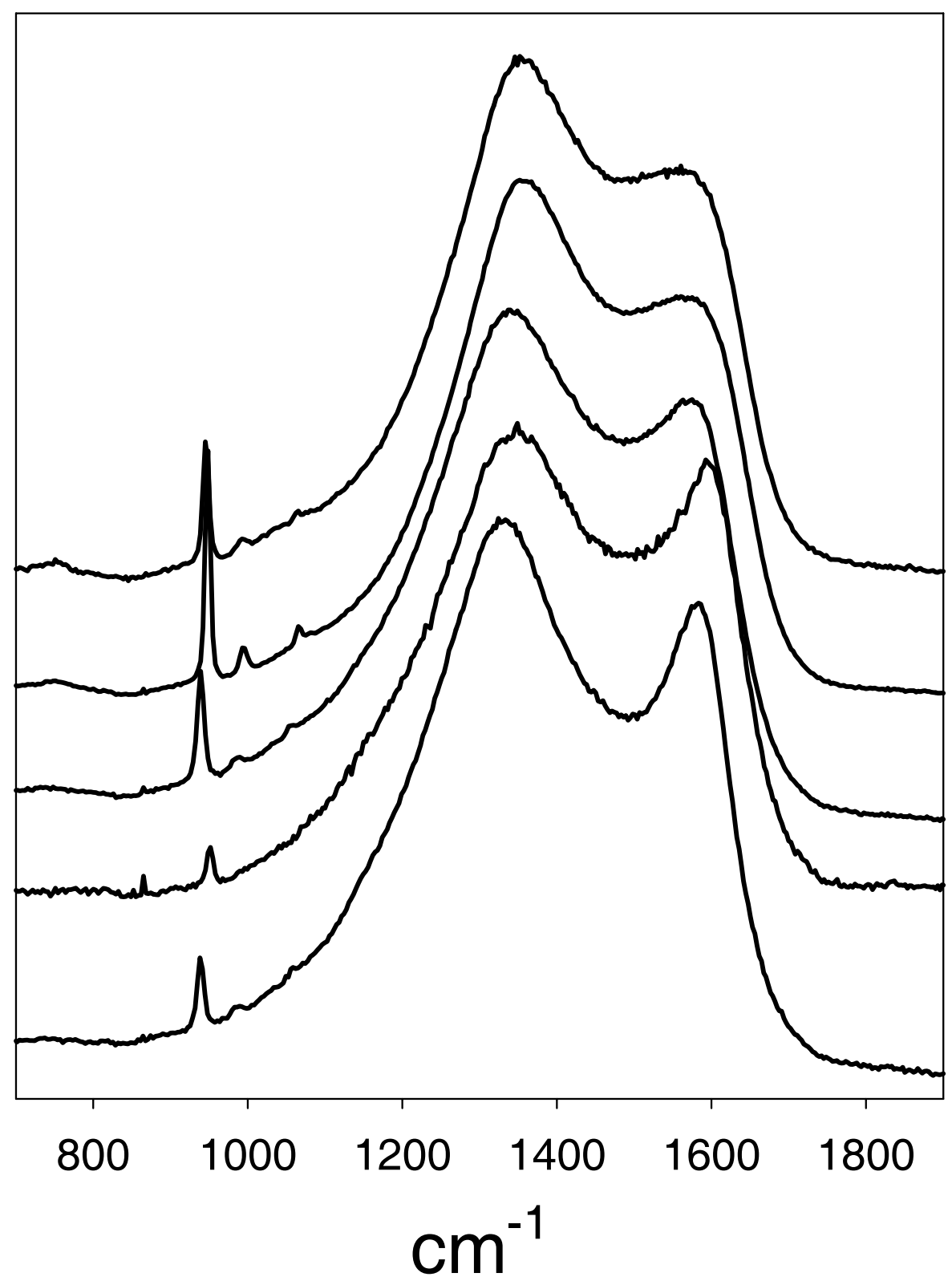

Figure 1. 


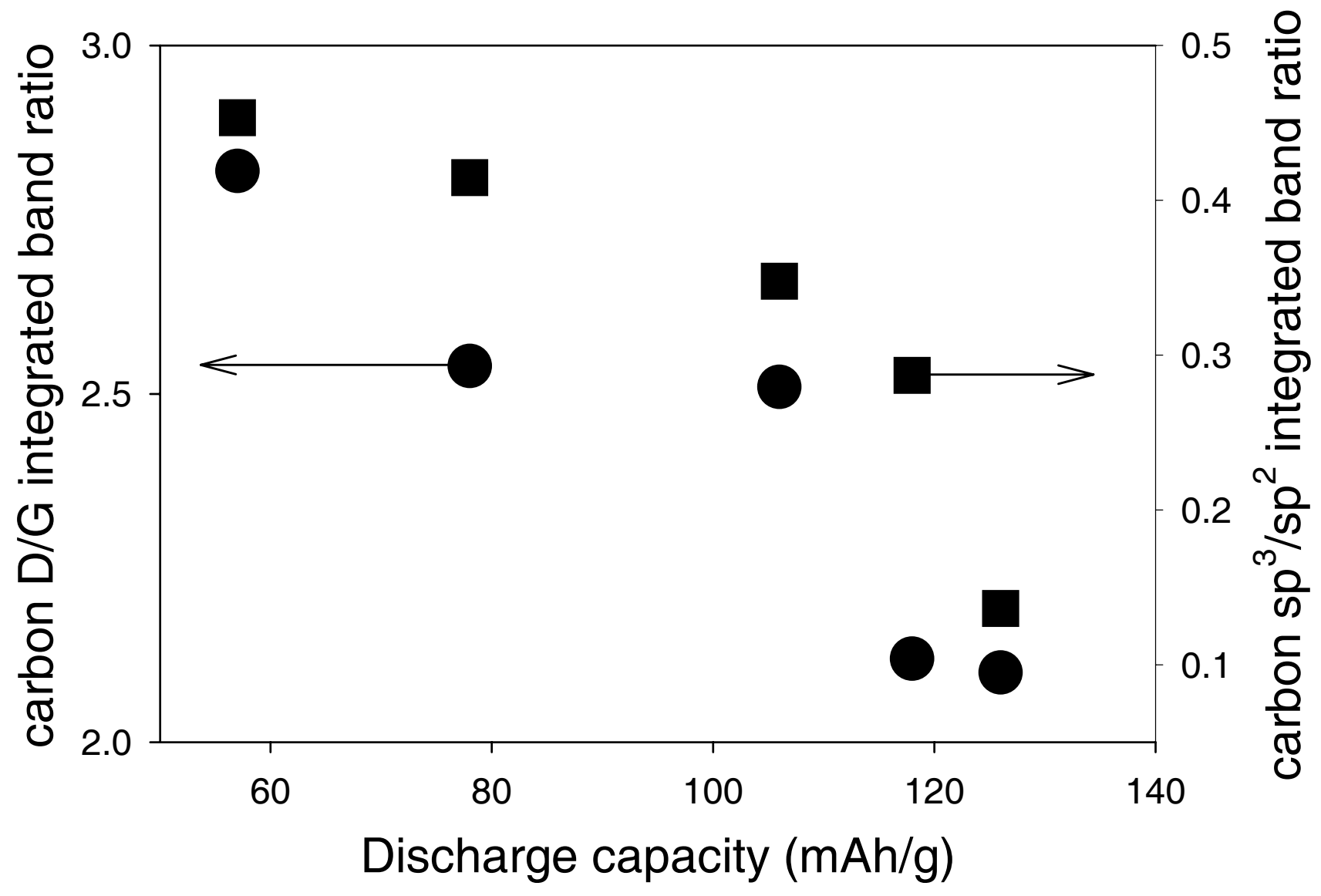

Figure 2. 


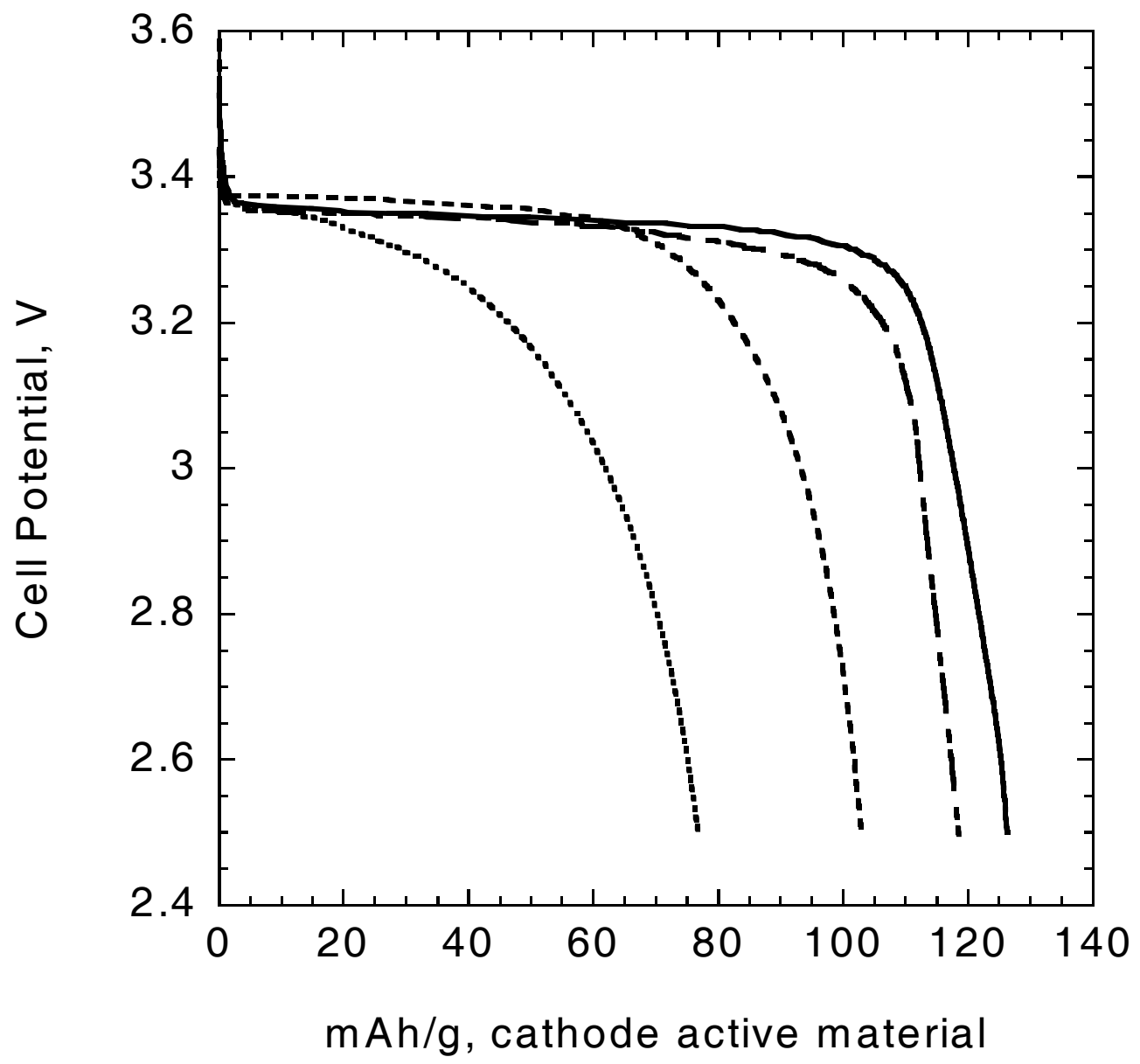

Figure 3. 